\title{
PKM PENERAPAN PLTS PADA KAWASAN PERTANIAN HIDROGANIK PADI DI BENGKEL MIMPI KABUPATEN MALANG
}

\author{
Hery Budiyanto ${ }^{1}$, Aries Boedi Setiawan ${ }^{2}$, Aris Siswati ${ }^{3}$ \\ 1,2,3 Universitas Merdeka Malang \\ 1hery.budiyanto@unmer.ac.id, ${ }^{2}$ aries@unmer.ac.id., ${ }^{3}$ aris.siswati@unmer.ac.id
}

\begin{abstract}
Currently, rice farming land is getting narrower because it is pressed for housing. Ways are needed to utilize narrow land to develop a rice farming system, including hydrogenic farming, which is an organic cultivation system by planting rice on humus soil in plastic cups planted in a row of paralon pipes above fish ponds, integrating a hydro system (water circulation) nutritious and organic systems (without chemical fertilizers). This Community Partnership Program aims to deal with the problems experienced by service partners, namely the Self-help Agricultural and Rural Training Center "Bengkel Mimpi" in Malang Regency which carries out hydroganic rice cultivation, namely how to obtain alternative sources of electricity so that financial expenditures for electricity can be increased. So far, only state electricity company can save more/reduce, so that the solution and output target implemented in overcoming these problems is in the form of a solar power plant which is used to drive 12 hydraulic water pumps. The method of service is action research: discussion, design and application of solar power plants. After going through technical calculations, 6 @ 100 wp solar panels were installed, complete with support brackets, 3 @ 100 AH batteries, 1 solar charge controller, 1 of 3000 WA inverter, 12 water pumps. The advantage of this solar power plant is the design aspect of the solar panel support bracket which is made attractively resembles the shape of a sunflower. The test results have been carried out in sunny conditions this solar power plant produces 2,194 Watt Hours. The output of this Community Partnership Program can be used as a model for alternative sources of electricity in other villages nationally, especially on hydrogenic and hydroponic agricultural lands which are located far from the state electricity network.
\end{abstract}

Keywords: hydrogenic rice, action research, solar power generation

\section{PENDAHULUAN}

Beras merupakan makanan pokok lebih dari $95 \%$ penduduk Indonesia. Selain itu, bercocok tanam padi juga telah menyediakan lapangan pekerjaan bagi sekitar 20 juta rumah petani di pedesaan, sehingga dari sisi ketahanan pangan nasional fungsinya menjadi amat penting dan strategis (Rusdiana \& Maesya, 2017). Oleh sebab itu ketersediaan beras harus selalu terjamin karena dapat menyebabkan kerawanan bila terjadi kekurangan stok. Pesatnya laju pertumbuhan penduduk sebesar 1,31\% per tahun (lebih dari 271 juta jiwa pada tahun 2020) (Pangestika \& Prihtanti, 2020) menyebabkan meningkatnya kebutuhan terhadap beras sementara pertumbuhan produksinya tidak sebanding dengan permintaan, bahkan cenderung melandai (levelling 0ff). Petani yang kehilangan lahan sawahnya mayoritas mengalami penurunan pendapatan. Hal ini dikarenakan tingkat pendidikan dan ketrampilan para petani yang terbatas atau tergolong rendah sehingga mereka tidak dapat mengakses pekerjaan formal (Dewi \& Rudiarto, 2013). Para petani biasanya menggunakan tanah untuk media tanam, namun seiring dengan perkembangan kota lahan pertanian banyak yang berubah menjadi lahan permukiman dan fasilitas kota lainnya sehingga lahan pertanian menjadi semakin sempit. Pertanian Perkotaan (Urban Farming) adalah bertani dengan memanfaatkan lahan sempit atau intensifikasi lahan, guna memenuhi kebutuhan sayuran dan buah segar sehari-hari bagi masyarakat pemukiman/perumahan di perkotaan (Achmad, 2020). Kekurangan lahan untuk budidaya pertanian saat ini telah menimbulkan inovasi kearah intensifikasi 
pemakaian lahan berupa sistem hidroponik (Sudarmo, 2018). Tanaman yang digunakan untuk budidaya hidroponik adalah tanaman yang cepat panen dan memiliki perakaran yang dangkali. Budidaya hidroponik alternatif yang memanfaatkan media organik dan pupuk organik yang dikenal dengan hidroganik (Putra et al., 2020), berasal dari kata "Hidro" dan "Organik" yang didefinisikan sebagai sistem budidaya organik dengan memadukan sistem hidro dan sistem organik. Sumber nutrisi utama dari hidroganik ini diperoleh dari pupuk organik padat dan cair serta air kolam yang di-treatment sebagai nutrisi tanaman (Udin, 2017).

Keuntungan cara bercocok tanam sistem hidroganik padi adalah: 1) Hasil dan kualitas tanaman lebih tinggi; 2) Lebih terbebas dari hama dan penyakit; 3) Penggunaan air dan pupuk lebih hemat; 4) Dapat untuk mengatasi masalah tanah; 5) Dapat untuk mengatasi masalah keterbatasan lahan (Budiyanto, Haris, Setiawan, et al., 2019). Sedangkan keunggulannya adalah: 1) Tidak perlu pengolahan tanah; 2) Tidak perlu rotasi tanaman; 3) Hasil seragam; 4) Bersih 5) Hasil tinggi; 6) Tenaga kerja sedikit (efisien); 7) Lebih mudah dalam pemeliharaan; 8) Lebih mudah dalam mengganti tanaman baru; 9) Dapat merupakan tempat dan cara untuk memperbaiki mutu tanaman; 10) Tidak banyak gulma; 11) Pengendalian hama lebih mudah; 12) Tidak perlu penyemaian; 13) Lebih hemat bibit; 14) Perawatan mudah; 15) Tidak perlu irigasi; 16) Panen lebih mudah dan lebih maksimal; 17) Panen ikan; 18) Tidak membutuhkan air banyak; 19) Bisa dibuat disekitar rumah, di lahan kering, di atas bangunan dan halaman mall; 20) Panen yang dihasilkan lebih sehat karena tidak menggunak pupuk kimia dan pestisida kimia; 21) Dalam satu tahun bisa panen 4 kali. (Budiyanto, Haris, \& Boedi, 2019).

Kegiatan PKM ini berangkat dari adanya masalah sumber tenaga listrik yang merupakan salah satu kebutuhan dasar bagi pertanian padi pada kawasan pertanian hidroganik dan Pusat Pelatihan Pertanian dan Pedesaan Swadaya "Bengkel Mimpi" di Desa Kanigoro, Kecamatan Pagelaran, Kabupaten Malang, dimana terdapat 12 unit pertanian sistem hidroganik padi yang masing-masing unit membutuhkan pompa sirkulasi air. Selama ini tenaga listrik untuk menggerakkan pompa sirkulasi air berasal dari PLN sehingga cukup memberatkan bagi pengelola pertanian hidroganik padi "Bengkel Mimpi". Tujuan kegiatan PKM ini adalah mengatasi permasalahan beban biaya listrik pertanian hidroganik padi "Bengkel Mimpi" yang perlu sumber tenaga listrik alternatif agar pengeluaran keuangan untuk listrik yang selama ini hanya dari PLN dapat lebih dihemat/dikurangi.

Selama ini Bengkel Mimpi dalam mengelola tanaman padi maupun sayur secara hidroganik masih mengandalkan energi listrik PLN untuk menggerakkan pompa-pompa air di masing-masing unit hidroganik. Apabila aliran listrik padam maka pompa akan terhenti. Hal ini akan mempengaruhi kehidupan ikan yang selalu memerlukan air beroksigen. Sehingga memerlukan sumber energi listrik mandiri yang kontinyu selain listrik PLN. Solusi dan target luaran yang akan dilaksanakan dalam mengatasi permasalahan tersebut berupa pembangkit listrik tenaga surya (PLTS) untuk menggerakkan pompa air hidroganik dan lampu penerangan jalan di kawasan "Bengkel Mimpi”.

Program Kemitraan Masyarakat (PKM) ini bertujuan untuk menangani permasalahan utama yang dialami oleh Pusat Pelatihan Pertanian dan Pedesaan Swadaya "Bengkel Mimpi" di Dusun Krajan Desa Kanigoro RT 33 RW 03 Kecamatan Pagelaran Kabupaten Malang yaitu bagaimana mendapatkan sumber tenaga listrik alternatif agar pengeluaran keuangan untuk listrik yang selama ini hanya dari PLN dapat lebih dihemat/dikurangi. 


\section{METODE}

Artikel ini merupakan hasil Program Kemitraan Masyarakat (PKM) pada bulan April-November 2021 yang merupakan penelitian tindakan (action research) dan menggunakan metode deskriptif kualitatif dengan studi kasus "Bengkel Mimpi". Metode pelaksanaan meliputi 5 langkah, yaitu: a) Focus Group Discussion, b) Desain dan Perhitungan PLTS, c) Pemasangan PLTS, d) Pengujian dan Penggunaan PLTS di "Bengkel Mimpi", e) Evaluasi kegiatan.

\section{HASIL KARYA UTAMA DAN PEMBAHASAN Focus Group Discussion (FGD)}

PKM dimulai dengan FGD antara Tim PKM dengan kelompok "Bengkel Mimpi" untuk memetakan permasalahan yang terjadi/dialami oleh kelompok. Hasil diskusi awal mengerucut pada penggunaan sumber listrik alternatif berupa Pembangkit Listrik Tenaga Surya (PLTS) untuk menjalankan pompa-pompa sirkulasi hidroganik (Budiyanto, Haris, Setiawan, et al., 2019). Langkah awal dilakukan perhitungan komponen-komponen PLTS (panel surya, baterai, solar controller, dan inverter). Dilanjutkan dengan pembahasan tentang desain yang inovatif terutama pada bracket panel suryanya.
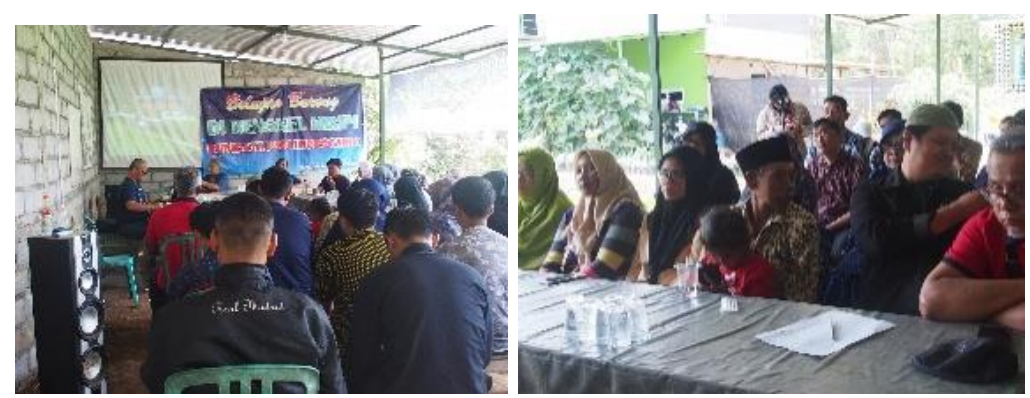

Gambar 1. FGD Tim PKM dengan Kelompok "Bengkel Mimpi”

\section{Desain dan Perhitungan}

Mengacu pada Suryani (Suryani et al., 2018) maka Desain Skematik Pertanian Hidroganik Padi dengan PLTS dapat dilihat pada gambar 1.

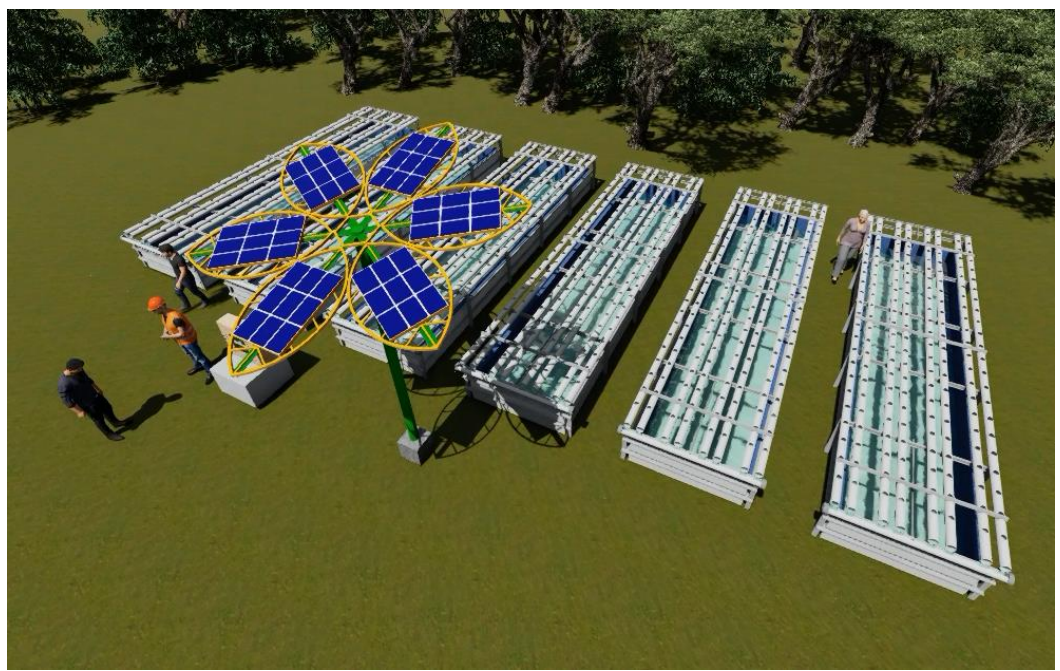

Gambar 2. Skematik PLTS untuk Pertanian Hidroganik dengan Energi Surya 
Pada skematik PLTS diperlihatkan sistem pengairan sebagai berikut: pengambilan air bersih menggunakan pompa air tandon bawah kemudian disalurkan ke kolam ikan hidroganik. Dari kolam hidroganik air dipompakan ke pipa-pipa paralon tempat menumbuhkan tanaman menggunakan pipa sirkulasi hidroganik. Sedangkan sumber tenaga listrik untuk kedua jenis pompa diambil dari inventer pada sistem pembangkit listrik tenaga surya.

Desain bracket panel surya dibuat dengan memperhatikan lingkungan pertanian sehingga bentuknya atraktif mengikuti bentuk bunga sebagaimana terlihat pada gambar 2 .
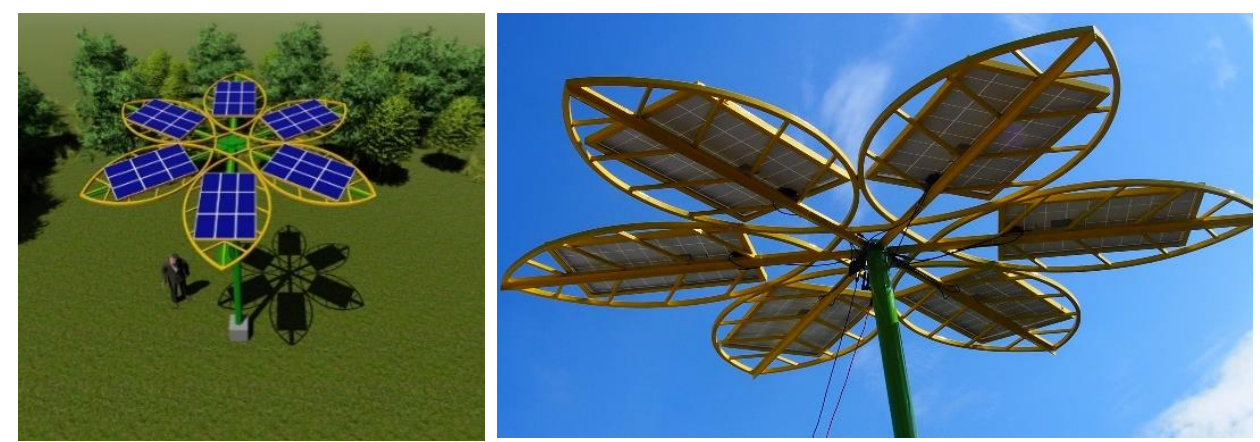

Gambar 3. Desain dan Aplikasi Bentuk Bracket Solar Panel

Perhitungan dilakukan untuk menjamin ketersediaan sumber listrik tenaga surya untuk menggerakkan minimal 12 pompa air $(12 \times 50 \mathrm{Watt}=600 \mathrm{Watt})$. Mengacu pada rumusan yang dibuat oleh Suryani dkk (Suryani et al., 2018), maka didapat jumlah komponen yang dibutuhkan adalah: 6 buah solar panel 100 wp 12 V lengkap dengan bracket penyangga, 3 buah battery $100 \mathrm{AH} 12 \mathrm{~V}, 1$ buah solar charge controller MPPT 60 A, 1 buah inverter PSW 3000 WA.

Listrik yang dihasilkan oleh panel surya dapat langsung digunakan atau disimpan lebih dahulu ke dalam baterai. Arus listrik yang dihasilkan adalah listrik dengan arus searah (DC). Panel surya yang digunakan adalah jenis polycrystalline ini mampu menghasilkan energi listrik di cuaca mendung atau berawan (Pratama \& Siregar, 2018). Rangkaian panel-panel surya didesain secara paralel, untuk memperoleh output tegangan dan arus yang diinginkan. Untuk memperoleh arus bolak balik (AC) diperlukan alat tambahan yang disebut inverter. Kemudian arus yang diperoleh dari inverter dapat menyuplai beban AC (Pratama \& Siregar, 2018).

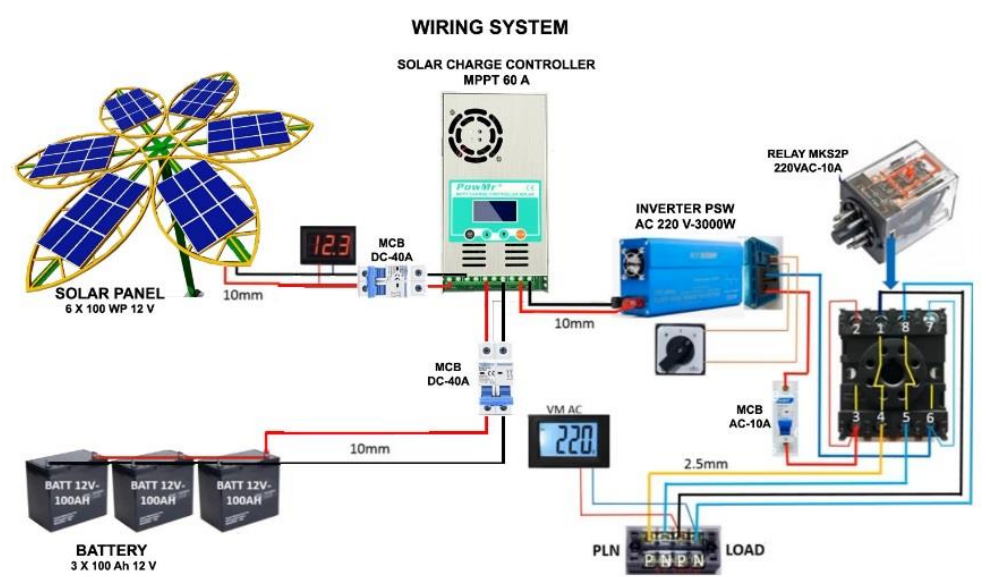

Gambar 4. Rangkaian PLTS untuk Pertanian Hidroganik Padi 


\section{Pemasangan PLTS}

Pemasangan PLTS dilaksanakan pada tanggal 29-30 juni 2021, dimulai dengan pemasangan bracket penyangga panel surya dilanjutkan dengan pemasangan power bank berupa solar charge controller, battery, dan inverter. Solar charge controller yang digunakan adalah jenis Maximum Power Point Tracking (MPPT) yang dapat menghasilkan power maksimum pengisian listrik dari panel surya menuju baterai (Dwidayanti et al., 2017). MPPT benar-benar sebuah sistem elektronik yang bisa menelusuri titik power maksimum power yang bisa dikeluarkan oleh sebuah panel surya (Winarno \& Natasari, 2017). Inverternya menggunakan jenis pure sine wave (PSW) atau gelombang sinus murni yang menghasilkan output gelombang sinus identik dengan daya keluar dari outlet listrik (Kalyani, 2015). Untuk baterai menggunakan jenis VRLA (Valve Regulated Lead Acid) yang banyak digunakan oleh praktisi PLTS (Samsurizal et al., 2021).
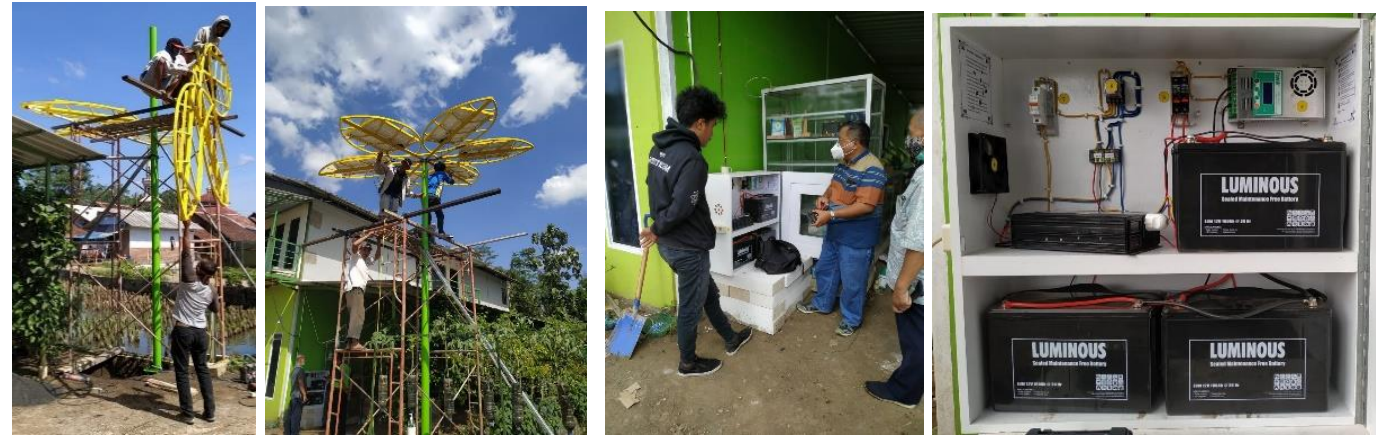

Gambar 5. Pemasangan PLTS

\section{Pengujian dan Penggunaan PLTS di "Bengkel Mimpi"}

Pengujian kemampuan PLTS dilakukan setelah seluruh komponen PLTS terpasang. Pengujian dilakukan pada tanggal 6 Juli 2021 dari jam 06.00 hingga jam 17.30. dengan hasil sebagai berikut:

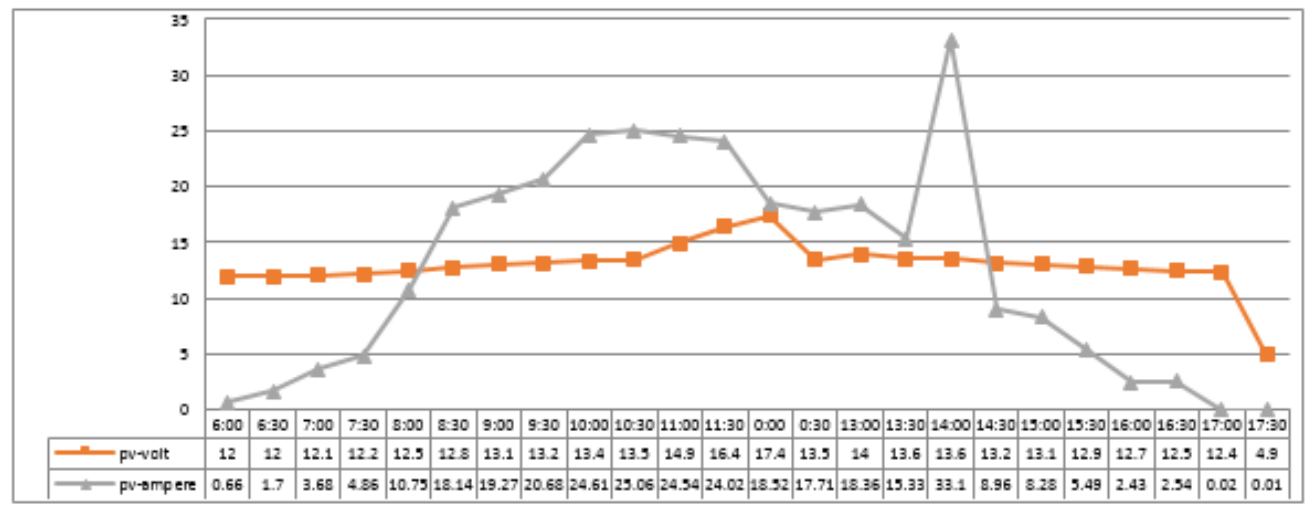

Gambar 6. Grafik Kemampuan PLTS

Hasil pengujian yang diperlihatkan pada Gambar 5 menyatakan bahwa pengisian baterai efektif pada jam 7.30 hingga 16.00. Kemampuan daya PLTS yang didapan dalam 1 hari adalah 2.194 WattJam yang mampu untuk menggerakkan pompa air sirkulasi sejumlah 7 buah pompa selama 10 jam terus menerus.

Hasil pengujian tersebut menunjukkan bahwa PLTS dapat membantu meringankan biaya pembayaran listrik PLN sebesar 7/12 x 100\% = 58\% dari seluruh kebutuhan tenaga listrik untuk menggerakkan pompa sirkulasi hidroganik di "Bengkel Mimpi" 


\section{Evaluasi Kegiatan}

Kegiatan penerapan PLTS telah berhasil dilaksanakan pada kawasan pertanian "Bengkel Mimpi" di Desa Kanigoro, Kecamatan Pagelaran, Kabupaten Malang. PLTS ini terdiri dari 6 buah panel surya $100 \mathrm{WP}, 3$ buah baterai VRLA 100 Ah 12 V, 1 buah Solar Charge Controller MPPT 40A, Inverter PSW 3.000 Watt telah mampu mengurangi beban penggunaan listrik PLN pada kompleks pertanian hidroganik padi hingga 58\% dari penggunaan sebelumnya.

\section{KESIMPULAN}

Pembangkit Listrik Tenaga Surya (PLTS) merupakan fasilitas yang sangat diperlukan oleh kelompok tani "Bengkel Mimpi" yang bergerak di bidang pertanian hidroganik padi, dimana diperlukan sumber listrik untuk menggerakkan pompa sirkulasi air hidroganik. Permasalahan sering terjadi ketika ada pemadaman listrik PLN dan beban daya bulanan listrik dari 12 buah pompa sirkulasi hidroganik cukup besar sehingga diperlukan sumber energi listrik selain PLN. Program Kemitraan Masyarakat (PKM) Pengembangan Kawasan Pertanian Hidroganik Padi "Bengkel Mimpi" Menggunakan Sumber Energi Mandiri Fotovoltaik telah berhasil menyelesaikan permasalahan-permasalahan tersebut, yaitu: 1) Pembuatan Desain PLTS dibuat atraktif dan menyesuaikan dengan lingkungan pertanian; 2) Meskipun kemampuan PLTS yang sudah terpasang baru mencapai 58\% dari kebutuhan sumber daya listrik yang ada, namun hasil tersebut telah banyak membantu kelompok "Bengkel Mimpi"; 3) Keberadaan PLTS di "Bengkel Mimpi" Desa Kanigoro Kecamatan Pagelaran Kabupaten Malang ini telah menjadi perhatian dari berbagai pihak yang mengunjungi "Bengkel Mimpi" sehingga ada kemungkinan untuk mengembangkannya di daerah lain.

\section{UCAPAN TERIMAKASIH}

Ucapan terima kasih ditujukan kepada:

1. Kementerian Pendidikan, Kebudayaan, Riset dan Teknologi yang telah menyediakan dana bagi pelaksanaan PKM tahun 2021;

2. Prodi Arsitektur, Prodi Elektro, Prodi Ekonomi Pembangunan, Lembaga Penelitian dan Pengabdian kepada Masyarakat Universitas Merdeka Malang, yang telah mendukung pelaksanaan pengabdian ini.

3. Komunitas "Bengkel Mimpi", yang telah berpartisipasi dan sebagai Mitra pengabdian dalam Program Kemitraan Masyarakat.

\section{DAFTAR PUSTAKA}

Achmad, R. (2020). Eksistensi Lahan Usahatani padi di Kota Makassar. Jsep, 16(2), 175-184. https://journal.unhas.ac.id/index.php/jsep/article/download/7274/pdf/33547

Budiyanto, H., Haris, M., \& Boedi, A. (2019). The Bamboo Greenhouse Technology for Hydroganic Crops with Independent Photovoltaic Electricity. International Journal of Science and Engineering Applications, 8, 517-521. https://doi.org/10.7753/IJSEA0812.1004

Budiyanto, H., Haris, M., Setiawan, A. B., Sonalitha, E., \& Iqbal, M. (2019). Teknologi Greenhouse Hidroganik dengan Tenaga Listrik Mandiri. Seminar Nasional Infrastruktur Berkelanjutan Era Revolusi Industri 4.0, 2, 6. https://ejournal.itn.ac.id/index.php/semsina/article/view/2220

Dewi, N. K., \& Rudiarto, I. (2013). Identifikasi Alih Fungsi Lahan Pertanian dan Kondisi Sosial Ekonomi Masyarakat Daerah Pinggiran di Kecamatan Gunungpati Kota Semarang. Jurnal Wilayah Dan Lingkungan, 1(2), 175. https://doi.org/10.14710/jwl.1.2.175-188 
Dwidayanti, R., Gusmedi, H., \& Ratna, S. (2017). Optimasi Pengisian Daya Baterai Pada Panel Surya Menggunakan Maximum Power Point Tracking ( MPPT ). Jurnal Rekayasa Dan Teknologi Elektro, 11(1), 21-31.

Kalyani, V. L. (2015). Green Energy: The Need of the World. Journal of Management Engineering and Information Technology, 2(October), 18-26.

Pangestika, M., \& Prihtanti, T. M. (2020). Perbandingan Nilai Tukar Petani (Ntp) Antarsubsektor Pertanian Di Indonesia. AGRISAINTIFIKA: Jurnal Ilmu-Ilmu Pertanian, 4(1), 30. https://doi.org/10.32585/ags.v4i1.842

Pratama, D. A., \& Siregar, I. H. (2018). Uji Kinerja Panel Surya Polycrystallin 100WP. JPTM, 6(3), 79-85.

Putra, A. R. D., Mardiyani, S. A., \& Nurhidayati, N. (2020). Peran Vermikompos terhadap Morfofisiologi Kangkung Hidroganik. APutra, A. R. D., Mardiyani, S. A., \& Nurhidayati, N. (2020). Peran Vermikompos Terhadap Morfofisiologi Kangkung Hidroganik. Agrotechnology Research Journal, 4(2), 70. Https://Doi.Org/10.20961/Agrotechresj.V4i2.41125grotechnology Research Journal, 4(2), 70. https://doi.org/10.20961/agrotechresj.v4i2.41125

Rusdiana, S., \& Maesya, A. (2017). Pertumbuhan Ekonomi Dan Kebutuhan Pangan Di Indonesia. Agriekonomika, 6(1). https://doi.org/10.21107/agriekonomika.v6i1.1795

Samsurizal, S., Aji, M. T., \& M, K. T. (2021). Pemanfaatan Tenaga Surya Pada Photovoltaic Jenis Polycristaline Untuk Catu Daya Tanaman Hidroponik. Energi \& Kelistrikan, 13(1), 58-66. https://doi.org/10.33322/energi.v13i1.984

Sudarmo, A. P. (2018). Pemanfaatan pertanian secara hidroponik untuk mengatasi keterbatasan lahan pertanian di Daerah Perkotaan. In A. Lilik Aslichati, Tutisiana, Adi Suryanto (Ed.), Seminar Nasional Pengabdian Kepada Masyarakt Universitas Terbuka (pp. 1-8). Universitas Terbuka.

Suryani, A., Fadhillah, A. P., Saichu, \& Mubarok, H. (2018). Instalasi Pembangkit Listrik Tenaga Surya Dos \& Don 'ts (B. Ramadhani (ed.); 1st ed.). Deutsche Gesellschaft für Internationale Zusammenarbeit (GIZ) $\mathrm{GmbH}$. http://ebtke.esdm.go.id/post/2018/08/31/2007/buku.panduan.instalasi.pembangkit.listrk.ten aga.surya

Udin, A. (2017). BBPP Ketindan Kembangkan Sayuran Organik Dengan Hidroganik. BBPP Ketindan, 1. http://www.swadayaonline.com/artikel/377/BBPP-Ketindan-KembangkanSayuran-Organik-Dengan-Hidroganik/

Winarno, I., \& Natasari, L. (2017). Maximum Power Point Tracker (MPPT) Berdasarkan Metode Perturb and Observe Dengan Sistem Tracking Panel Surya Single Axis. Seminar Nasional Sains Dan Teknologi 2017, November, 1-9. 